\title{
Factors Affecting the Residing Preference of China's Floating Elderly Population
}

\author{
Qihui Zhang1, Yinlong Jia² \\ ${ }^{1}$ School of Management Science, Chengdu University of Technology, Chengdu, China \\ ${ }^{2}$ School of Public Affairs, University of Science and Technology of China, Hefei, China \\ Email: yinlong@mail.ustc.edu.cn
}

How to cite this paper: Zhang, Q. H., \& Jia, Y. L. (2021). Factors Affecting the Residing Preference of China's Floating Elderly Population. Open Journal of Social Sciences, 9, 62-82.

https://doi.org/10.4236/jss.2021.95006

Received: April 21, 2021

Accepted: May 8, 2021

Published: May 11, 2021

Copyright (c) 2021 by author(s) and Scientific Research Publishing Inc. This work is licensed under the Creative Commons Attribution International License (CC BY 4.0).

http://creativecommons.org/licenses/by/4.0/

(c) (i) Open Access

\begin{abstract}
In recent years, the floating elderly population (FEP) is constantly rising in China, and the flow of the elderly in the future will inevitably affect the redistribution of elderly population, including the nursing demands of the elderly, even the spatial matching problems on providing public resources and facilities. Therefore, based on the data of China Migrants Dynamic Survey (CMDS) in 2016, this paper, taking Pierre Bourdieu's cultural, economic and social capital as the theoretical framework, aims to analyze the factors affecting the residing preference of the FEP. The investigation shows that the model has a good number of indicators, significantly reflecting the influence of the variables of different capitals on the residing preference, and among them, the social capital exerts the most remarkable influence. In accordance with the analyzing results, some public policy suggestions on strengthening the government elderly service, improving the community comprehensive service and building a good elderly economic service have been raised so as to enhance the residing preference of the FEP.
\end{abstract}

\section{Keywords}

Floating Elderly Population (FEP), Residing Preference, Cultural Capital, Economic Capital, Social Capital, 2016 China Migrants Dynamic Survey (CMDS)

\section{Introduction}

Nowadays, with the spread of Corona Virus Disease 2019 (COVID-19) around the globe, we recognize that the floating population is prone to increase the burden of public health, and the floating elderly population (FEP) are apt to be affected and more vulnerable. China, a country with a large floating population, is 
in it. With the continuous development of China's aging population and urbanization, as well as the increasingly expansion of population migration and mobility, the floating middle-aged and elderly population in China is constantly increasing in recent years (He \& Liu, 2019).

According to the results of China's Sixth National Census in 2010, China's floating population has risen to 221 million, of which the FEP has reached 9.344 million, accounting for $5.26 \%$ of the country's elderly population aged 60 and over, $5.79 \%$ of the whole floating population, and the number of the FEP in total has increased by 871,000 in five years (Hou \& Li, 2017). Because of the particularity of demographic structure in China, it is estimated that there will be more elderly people in the floating group in the future with the growth of children in the only-child families, the annual increase of the elderly population, and the trend of urbanization and population mobility.

Besides, since the FEP is one of the groups easy to be ignored, on the one hand, the proportion of the FEP in the floating population is relatively small, not the majority; on the other hand, the FEP has completed the birth stage, employment stage and education stage in their life process of growth, so it is also considered as a group without special problems (Chen, 2015). However, in the future, a large number of elderly flows will inevitably influence the redistribution of the elderly population in China, which in turn can possibly affect the nursing demands or care needs of the elderly and the spatial matching problems on providing public resources and facilities.

Therefore, it is necessary and reasonable to study the factors affecting the residing preference of the floating elderly and try to improve it.

\section{Literature Review}

In recent years, a large number of scholars have paid attention to the residing preference of the floating population in China from different perspectives, mainly on the attributes of the floating population and the factors affecting the residing preference. In the studies of the attributes of floating population, Jiang, Hou et al. (2004) find that the FEP in China mostly occur in the younger age group, and the major reasons for the population floating are manifested in demolishing and moving houses, joining relatives and friends, and accompanying family members. Besides, Qi (2004) points out that the main reason for FEP is to rely on their grown-up children, and Ma \& Chow (2006) think that age, education, income and marital status had a significant impact on the retirement migration of the elderly by examining the economic consequences of elderly seasonal residents in China; while Meng (2009) believes that the factors that determined the migration among the elderly in China were the outflow place, personal preference, the inflow place, and the benefits and costs of migration. Duan, Lv et al. (2013) have analyzed the current situation and main problems of the floating population in China and found that the floaters are facing challenges such as unemployment, lack of social security, inequality in children's education, and barriers in social integration based on the 2010 Population Census Data. Lv, 
Yang et al. (2019) argue that the overall size of elderly migration is increasing rapidly in China, and the elderly migration behavior is correlated with health status, income sources and closeness of the inter-generational relationship with their children based on the data from China's 2015 one-percent national population sample survey.

As for the residing preference of the floating population, most scholars take the migrant workers and other labor groups as the research object, while few considered about the floating elderly population (FEP). In addition, the basic characteristics of the floating labor groups and the FEP are different, and the factors that affect the residing preference are also not necessarily the same. Li (2011) has conducted 432 questionnaires on the elderly over 60 years old in Dalian and investigated the social-psychological factors and living consciousness of the FEP. By analyzing, the FEP suffered from high loneliness are prone to failure in residing; The FEP who adapt to social life have a strong sense of settlement, and those who have a strong sense of stability in the community are also inclined to settle down; but, those who lack a sense of belonging tend to be more likely to return home and have an uncertain desire to reside. Shen (2012) states that the income, education level, willingness to integrate, urban public service, residence time and a number of people to move out all can affect the preference by analyzing the survey data from six cities in China.

Jing \& Zhu (2015) have discussed the factors affecting the flow of the elderly people according to the survey data of the FEP in Xi'an rural areas. The results showed that more than half of the rural floating elderly are eager to retire in the city, and the age, lifestyle, health, status, relationship with the children they live with, community participation, housing conditions and spouse's willingness to re-settle play an important role in their residing preference. Taking Fujian Province in China as an example, Chen \& Wu (2016) have investigated the factors of urban and rural life, family members that influence the urban dwellers' choices. Based on the new immigration economics, these thoughts are notably interpretative and convincing in the discussion of the family member factor variables used by the elderly to explain the urban residing preference. Jing (2019) has conducted GIS technology to analyze the elderly migrants in China and their spatial distribution and willingness to stay in destination. The results show that compared with the registered elderly, the elderly migrants are more male, younger, less educated, more widowed, more agricultural accounts, and lower family income.

The above studies have made valuable explorations on the attributes of the floating population and the factors affecting the residing preference in China. But in general, there are still few relevant researches on the residing preference of the FEP at the national level. Besides, in some researches on the residing preference of the FEP, the theoretical basis for the classification of the independent variable, the influencing factor, is lacking or unconvincing; when discussing the factors affecting the preference, more emphasis is placed on the demographic factors, and there is also a lack of classification. Therefore, this paper aims to 
make a systematic explanation on the factors affecting the residing preference of the FEP in China, and tries to put forward some suggestions on the public policies to improve the residing preference by taking Pierre Bourdieu's three types of capital theory, namely cultural, economic and social capital, as the analytical framework.

\section{Data and Methodology}

\subsection{Data}

This study is based on the data of China Migrants Dynamic Survey (CMDS) released by National Health and Family Planning Commission (NHFPC) of China in 2016. Samples are randomly collected from the highly concentrated inflow areas of the floating population in 31 provinces (including 5 autonomous regions and 4 municipalities) and Xinjiang Production and Construction Corps in China. The CMDS is conducted for the residents live in the inflow areas for more than one month but not belong to the district, such as the county or city, and the floating population aged 15 and over was sampled by using PPS method (probability proportional to size) of stratification, multi-stage and scale proportion.

According to the survey manual of CMDS, the elderly population refers to the people who are aged 60 and over in May 2016, and there are 4907 samples (the FEP, $\geq 60$ years old) collected in total. This data serves as the information on the socio-demographic characteristics, the economic, social and cultural capital, the health condition and the children of the FEP in China. The dependent variable is the residing preference of the FEP in the inflow areas, which is manipulated by the question and answer "Do you plan to live in the local area for a long time ( $\geq 5$ years)". The answer items include "Yes" (plan to stay), "No" (not plan to stay) and "I Don't Know". Thus, in this way, this data is basically in line with the quantitative and qualitative analysis of the residing preference of the FEP.

\subsection{Methodology}

Adopting a quantitative approach for China's floating population data, the discussion and analysis of this study are on the basis of Pierre Bourdieu's theory, which has a great influence in Europe. Bourdieu takes cultural capital, economic capital and social capital to explore the inter-generational inheritance mechanism of the ruling class (Li, 2007). He believes that cultural capital usually exists in the form of education quality system, which can be transformed into economic capital under certain conditions; economic capital can be directly converted into money and exist in the form of private property rights, while social capital, defined by social obligations, exists in the form of high-value identity system and can be turned into economic or cultural capital under some certain conditions (Bourdieu, 1986; Coleman, 1998). From this perspective, Bourdieu's theory on these three types of capital can help us to explore and discuss the factors affecting the residing preference of the FEP (Li, Gong et al., 2016). There- 
fore, the dependent variable in this study is the residing preference of the FEP in the inflow area. In the effective samples collected, as shown in Table 1, there are 3410 floating elderly people planning to reside in the inflow area for a long time ( $\geq 5$ years), $69.5 \%$ of the whole; while 540 choose "NO", $11 \%$; and 957 answer "I Don't Know", $19.5 \%$.

The independent variables include the socio-demographic characteristics of the elderly, the flow characteristics of the elderly, and the economic and social characteristics. Besides, there are 4 variables selected for individual characteristics: gender, age, marital status and household registration; 2 are selected for cultural capital variables: education level and health education; 3 for economic capital variables: working situation, local housing purchase and endowment insurance; 5 for social capital variables: health records, flow reasons, number of people living together, individual flow and inflow duration. All the independent variables are corresponding to the question and answer items in the questionnaire. As for the problem that the model cannot be solved due to too few samples of individual variable categories, the corresponding data has been processed together in this paper. The detailed definition and evaluation of variables are shown in Table 2. By applying the Stata.14 software and multiple logistic regression models, and further testing the goodness of fit, pseudo-likelihood ratio, it aims to find out how the social population characteristics, cultural capital, economic capital and social capital of the respondents influence the residing preference of the FEP.

\section{Current Situation and Characteristics of the FEP in China}

\subsection{Current Situation of the FEP in China}

\section{Economic Situation of the FEP in China}

We choose whether or not he/she is employed (based on the answer to the question "have you worked for more than one hour being paid in the week before May 1st?" in the questionnaire), whether to purchase a house in the inflow place and whether to participate in endowment insurance (including the new rural insurance, pension, etc.) as indicators for the analysis of economic status.

Due to the constraints of age, physical condition and other factors, the economic status of the floating elderly is not ideal. In terms of the income, a superposition chart of the monthly income and expenditure in all samples has been made to analyze the income and expenditure of the FEP (see Figure 1). The vertical axis is the amount of income/expenditure (because only the overall situation

Table 1. Frequency of planning to reside ( $\geq 5$ years) of the FEP.

\begin{tabular}{ccc}
\hline Answer & Frequency & Pct. (\%) \\
\hline Yes & 3410 & 69.5 \\
No & 540 & 11.0 \\
I Don't Know & 957 & 19.5 \\
\hline
\end{tabular}




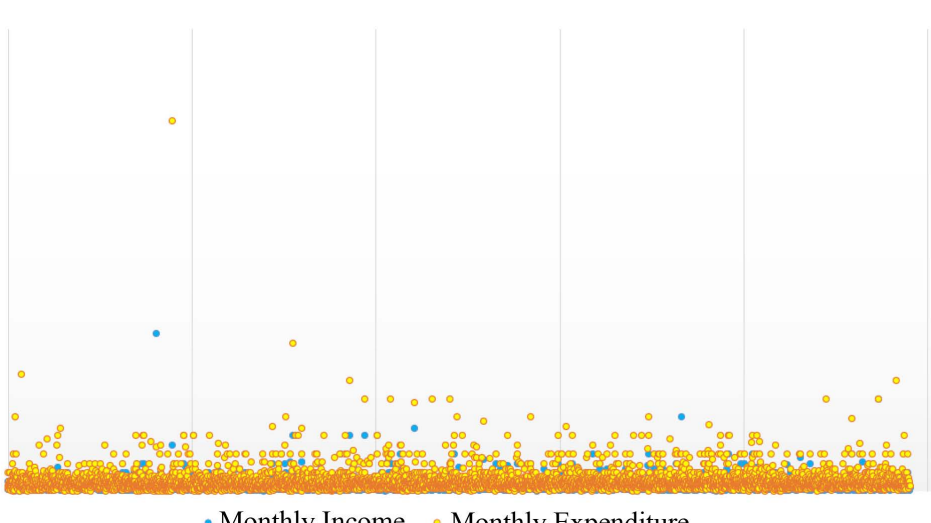

- Monthly Income Monthly Expenditure

Figure 1. Monthly income and expenditure of the whole family.

Table 2. List of variable evaluation.

\begin{tabular}{|c|c|c|c|c|}
\hline Variable & Evaluation & Sample & Mean & $\begin{array}{l}\text { Standard } \\
\text { Deviation }\end{array}$ \\
\hline \multicolumn{5}{|c|}{ Socio-demographic Characteristics } \\
\hline Gender & $1=$ male, $2=$ female & 4907 & 1.42 & 0.493 \\
\hline Age & $1=60-63,2=64-67,3=$ aged $\geq 67$ & 4907 & 1.94 & 0.867 \\
\hline Marital status & $1=$ married, $2=$ single & 4907 & 1.81 & 0.39 \\
\hline $\begin{array}{l}\text { Household } \\
\text { registration }\end{array}$ & $1=$ agricultural, $2=$ non-agricultural & 4907 & 1.43 & 0.496 \\
\hline \multicolumn{5}{|c|}{ Cultural Capital } \\
\hline Education level & $1=$ low, $2=$ medium, $3=$ high & 4907 & 2.69 & 1.137 \\
\hline Health Education & $1=$ yes, $2=$ no & 4907 & 0.96 & 0.493 \\
\hline \multicolumn{5}{|c|}{ Economic Capital } \\
\hline Working situation & $1=$ employed, $2=$ unemployed & 4907 & 1.73 & 0.45 \\
\hline $\begin{array}{l}\text { Local housing } \\
\text { purchase }\end{array}$ & $1=$ yes, $2=$ no & 4907 & 1.52 & 0.499 \\
\hline $\begin{array}{l}\text { Endowment } \\
\text { insurance }\end{array}$ & $1=$ yes $($ participated $), 2=$ no, $3=$ not known & 4907 & 1.35 & 0.491 \\
\hline \multicolumn{5}{|c|}{ Social Capital } \\
\hline $\begin{array}{l}\text { Number of people } \\
\text { living together }\end{array}$ & number of people living in the same family & 4907 & 2.77 & 1.387 \\
\hline Individual flow & $1=$ yes, $2=$ no & 4907 & 1.79 & 0.405 \\
\hline Health records & $\begin{array}{c}1=\text { yes }(\text { established }), 2=\text { no }(\text { not established }) \\
3=\text { not known }\end{array}$ & 4907 & 2.04 & 1.087 \\
\hline Inflow duration & $\begin{array}{c}1=<1 \text { year, } 2=1-2 \text { years, } 3=3-4 \text { years, } \\
4=5-9 \text { years, } 5=\geq 10 \text { years }\end{array}$ & 4907 & 3.67 & 1.257 \\
\hline Flow reasons & $\begin{array}{l}1=\text { work } / \text { business, } 2=\text { take care of children, } \\
3=\text { family members move along, } 4=\text { removal } \\
\text { and relocation, } 5=\text { stay with relatives and } \\
\text { friends, } 6=\text { look after the elderly, } 7=\text { others }\end{array}$ & 4907 & 2.77 & 1.826 \\
\hline
\end{tabular}

Note: $0=$ missing value. 
of income and expenditure is analyzed, detailed data are not listed), and the horizontal axis is the number of samples. In Figure 1, it can be seen that the monthly income and expenditure of the elderly migrant families are basically balanced, and the income is more than the expenditure, but there are also a few cases where the expenditure is greater than the income. In addition, the statistics show that $28.2 \%$ of the floating elderly in China have jobs, $47.6 \%$ have bought a house in the inflow area, and $65.4 \%$ have participated in endowment insurance. From Figure 2, it can be noticed that "work/business" is the main reason for the population flow, indicating that poor economic conditions but good physical fitness of the elderly is one of the reasons for their pursuit of economic development. This can also be proved by the purchase of endowment insurance among the FEP, which suggests that the economic situation of the FEP in China is not ideal, and the flow trend guided by the pursuit of economic interests is still the mainstream. In the $28.2 \%$ of the FEP with jobs, the occupations are still dominated by business, while other occupations are mostly simple low-level labor (see Table 3).

\section{Social Situation of the FEP in China}

According to Table 4, 79.3\% of the FEP in China do not migrate alone, and most of the floating elderly do not live alone in such a large number of floating. The number of people living in the same family is the most common among 1 to 3 , accounting for $75.7 \%$, which is also in line with the above analysis of the reasons for the flow. In addition, 93.2\% of the FEP in China have lived in the inflow area for more than one year. In terms of census standards, they become as permanent residents at local community, and the household registration becomes a symbol of the flow. When integrating into the inflow areas, $75.6 \%$ of the elderly have received health education in the community, $43.4 \%$ have established health records, while $42.9 \%$ have not established but once heard of that. Therefore, it seems that the social status of the FEP in China is relatively optimistic. The floating elderly have much more social interaction and contact in the community, so that they can better integrate into the inflow area.

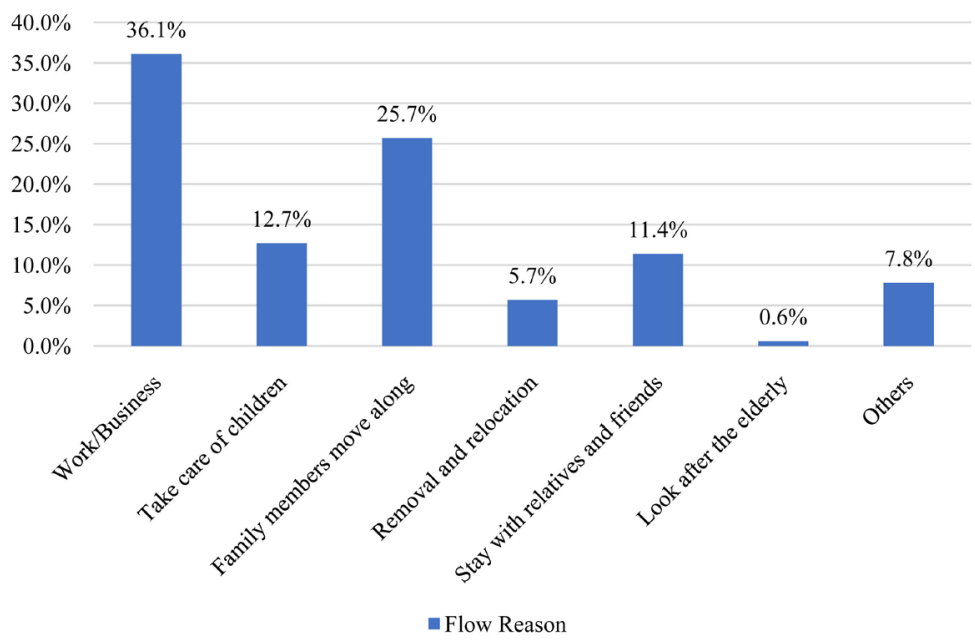

Figure 2. The causes of the subjective flow of the FEP in China. 
Table 3. Main occupation of the FEP in China.

\begin{tabular}{|c|c|c|c|}
\hline Main Occupation & $\begin{array}{l}\text { Pct. } \\
\text { (\%) }\end{array}$ & Main Occupation & $\begin{array}{l}\text { Pct. } \\
\text { (\%) }\end{array}$ \\
\hline $\begin{array}{l}\text { Officials in state organs, } \\
\text { party mass organizations, } \\
\text { enterprises and institutions }\end{array}$ & 0.1 & Cleaner & 3.6 \\
\hline Professional and technical personnel & 0.9 & Security staff & 2.9 \\
\hline $\begin{array}{l}\text { Civil servants, clerks } \\
\text { and related personnel }\end{array}$ & 0.1 & Decorator & 0.5 \\
\hline Businessmen & 4.6 & Other business and service personnel & 3.3 \\
\hline Small retailer & 2.1 & $\begin{array}{l}\text { Production personnel of agriculture, } \\
\text { forestry, animal husbandry, } \\
\text { fishery and water conservancy }\end{array}$ & 2.2 \\
\hline Catering employees & 2.1 & Production staff & 1.3 \\
\hline Housekeeping personnel & 0.4 & Transport workers & 0.3 \\
\hline Builder & 1.3 & Without fixed occupations & 1.2 \\
\hline $\begin{array}{c}\text { Other production and } \\
\text { transportation equipment } \\
\text { operators and related personnel }\end{array}$ & 0.4 & Others & 1.0 \\
\hline
\end{tabular}

Note: $28.2 \%$ of the FEP have jobs in which various occupations account for.

Table 4. Frequency of the social situation of the FEP in China.

\begin{tabular}{|c|c|c|c|}
\hline \multicolumn{2}{|l|}{ Categories } & \multirow{2}{*}{$\begin{array}{c}\text { Frequency } \\
3714\end{array}$} & \multirow{2}{*}{$\begin{array}{c}\text { Pct. (\%) } \\
75.7\end{array}$} \\
\hline & $1-3$ & & \\
\hline Number of people living together & $4-6$ & 1138 & 23.2 \\
\hline & $>6$ & 55 & 1.1 \\
\hline \multirow{2}{*}{ Individual flow } & yes & 1014 & 20.7 \\
\hline & no & 3893 & 79.3 \\
\hline \multirow{2}{*}{ Health education } & yes & 3709 & 75.6 \\
\hline & no & 506 & 10.3 \\
\hline \multirow{3}{*}{ Health records } & yes & 2131 & 43.4 \\
\hline & no & 2106 & 42.9 \\
\hline & not known & 670 & 13.7 \\
\hline \multirow{5}{*}{ Inflow duration } & $<1$ year & 336 & 6.8 \\
\hline & 1 - 2 years & 742 & 15.1 \\
\hline & $3-4$ years & 822 & 16.8 \\
\hline & 5 - 9 years & 1315 & 26.8 \\
\hline & $\geq 10$ years & 1692 & 34.5 \\
\hline
\end{tabular}

\section{Flow Situation of the FEP in China}

In the era of great transportation and information, the migration becomes easier and faster. At present, the flow of the FEP in China mainly occurs as 
trans-provincial migration and trans-city migration in the same province, respectively $40.4 \%$ and $38.3 \%$ of the whole. The western region becomes a relatively centralized area of the FEP, probably because of the comfortable climate, fresh air and slow pace of life, with a proportion of up to $41.2 \%$, followed by the eastern region, the northeast region, and the central region in China (see Figure 3 ).

\subsection{The Characteristics of the FEP in China}

\section{Socio-demographic Characteristics of the FEP in China}

When analyzing the characteristics of the floating population, it mainly focuses on the gender, age, household registration, nationality and marital status, education level and so on. From these basic socio-demographic characteristics, it not only can explore the overall information of the FEP, but also help to put forward some related public policy suggestions based on the research results. According to the data of CMDS, the gender, age, household registration, marriage status and education level of the FEP are selected as the socio-demographic characteristics for discussion in this paper. Since the age in the questionnaire is self-administered, we summarize it into three stages so as to make it conform to the normal distribution. In addition, the education level is divided in detail in the original questionnaire, and based on the same considerations, the elderly who "didn't attend school" and "or just finished primary school" are classified into "low-level education"; the elderly who hold "secondary school/high school" and "junior high school" degrees are integrated into "medium-level education"; and others belong to the "higher education background". The individual characteristics on residing preference are shown in Table 5.

Firstly, the current FEP in China is mainly the younger Han people, and the overall age distribution is relatively average. In terms of age composition, the younger aged account for $67.8 \%$ of the total floating elderly surveyed, and the elderly aged 60 to 63 are $38.1 \%$. Secondly, at present, China's FEP are mainly dominated by male and agricultural households, but the distribution of male, female, agricultural and non-agricultural is relatively even, with $58.3 \%$ and

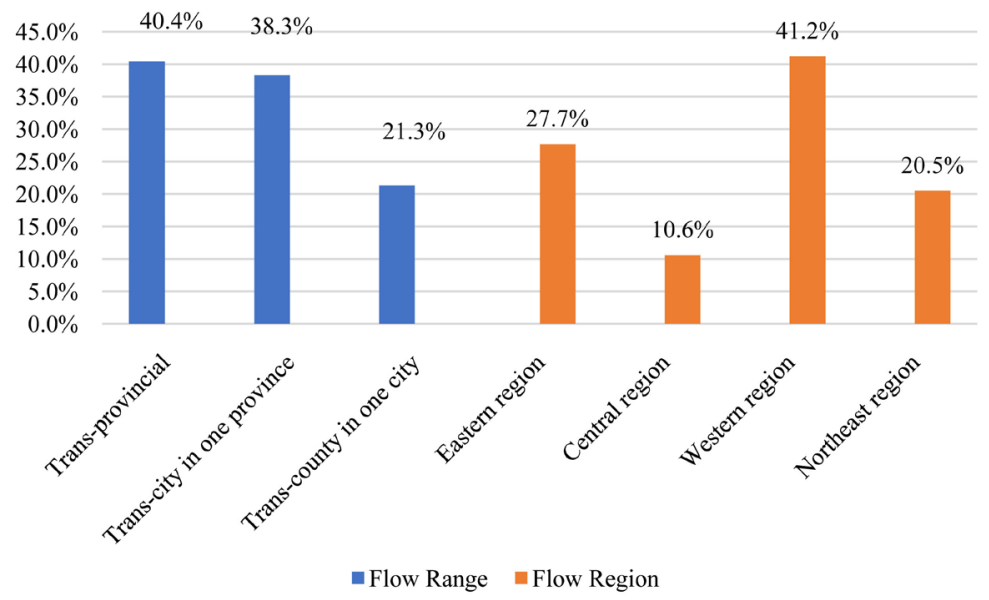

Figure 3. The inflow area of the FEP in China. 
Table 5. Individual characteristics on residing preference of the FEP in China.

\begin{tabular}{|c|c|c|c|c|c|}
\hline \multicolumn{2}{|c|}{ Categories } & \multicolumn{3}{|c|}{ Plan to Reside $\geq 5$ years } & \multirow{2}{*}{$\begin{array}{l}\text { Significance } \\
\text { (two-tailed } \\
\text { test) }\end{array}$} \\
\hline Categ & & \multirow{2}{*}{$\begin{array}{c}\text { Yes } \\
68.2 \%\end{array}$} & \multirow{2}{*}{\begin{tabular}{|c|} 
No \\
$12.0 \%$
\end{tabular}} & \multirow{2}{*}{$\begin{array}{c}\begin{array}{c}\text { Not } \\
\text { Known }\end{array} \\
19.8 \%\end{array}$} & \\
\hline & male & & & & \\
\hline Gender* & female & $71.3 \%$ & $9.6 \%$ & $19.0 \%$ & 0.088 \\
\hline \multirow{3}{*}{$\operatorname{Age}^{\star * *}$} & $60-63$ & $75.6 \%$ & $9.1 \%$ & $15.2 \%$ & \multirow{3}{*}{0.000} \\
\hline & $64-67$ & $68.5 \%$ & $11.5 \%$ & $20.0 \%$ & \\
\hline & $\geq 67$ & $63.1 \%$ & $12.8 \%$ & $24.1 \%$ & \\
\hline \multirow[b]{2}{*}{ Marital status } & married & $65.2 \%$ & $12.9 \%$ & $21.9 \%$ & \multirow[b]{2}{*}{0.005} \\
\hline & single & $70.5 \%$ & $10.6 \%$ & $19.0 \%$ & \\
\hline \multirow{2}{*}{ Household registration } & agricultural & $64.1 \%$ & $13.3 \%$ & $22.6 \%$ & \multirow{2}{*}{0.000} \\
\hline & non-agricultural & $76.5 \%$ & $8.1 \%$ & $15.5 \%$ & \\
\hline \multirow{3}{*}{ Education level ${ }^{\star * *}$} & low & $66.8 \%$ & $12.2 \%$ & $21.0 \%$ & \multirow{3}{*}{0.000} \\
\hline & medium & $70.8 \%$ & $10.4 \%$ & $18.8 \%$ & \\
\hline & high & $79.9 \%$ & $6.4 \%$ & $13.7 \%$ & \\
\hline \multirow{3}{*}{ Health education ${ }^{* * *}$} & 0 & $62.6 \%$ & $14.3 \%$ & $23.1 \%$ & \multirow{3}{*}{0.003} \\
\hline & yes & $70.7 \%$ & $10.3 \%$ & $19.0 \%$ & \\
\hline & no & $70.2 \%$ & $11.7 \%$ & $18.2 \%$ & \\
\hline \multirow{2}{*}{ Working situation ${ }^{\star * *}$} & employed & $54.6 \%$ & $18.3 \%$ & $27.2 \%$ & \multirow{2}{*}{0.000} \\
\hline & unemployed & $75.4 \%$ & $8.1 \%$ & $16.5 \%$ & \\
\hline \multirow{2}{*}{ Local housing purchase $\mathrm{e}^{\star * *}$} & yes & $86.4 \%$ & $3.8 \%$ & $9.9 \%$ & \multirow{2}{*}{0.000} \\
\hline & no & $54.2 \%$ & $17.6 \%$ & $28.2 \%$ & \\
\hline \multirow{3}{*}{ Endowment insurance ${ }^{\star \star \star}$} & yes & $71.2 \%$ & $10.5 \%$ & $18.3 \%$ & \multirow{3}{*}{0.000} \\
\hline & no & $66.3 \%$ & $12.1 \%$ & $21.6 \%$ & \\
\hline & not known & $58.1 \%$ & $6.5 \%$ & $35.5 \%$ & \\
\hline \multirow{3}{*}{$\begin{array}{l}\text { Number of people } \\
\text { living together }{ }^{* * *}\end{array}$} & $1-3$ & $69.0 \%$ & $11.3 \%$ & $19.7 \%$ & \multirow{3}{*}{$\begin{array}{c}\text { not } \\
\text { significant }\end{array}$} \\
\hline & $4-6$ & $71.2 \%$ & $10.1 \%$ & $18.7 \%$ & \\
\hline & $>6$ & $65.5 \%$ & $9.1 \%$ & $25.5 \%$ & \\
\hline \multirow{2}{*}{ Individual flow ${ }^{\star * *}$} & yes & $56.3 \%$ & $18.5 \%$ & $25.1 \%$ & \multirow{2}{*}{0.000} \\
\hline & no & $72.9 \%$ & $9.0 \%$ & $18.0 \%$ & \\
\hline \multirow{3}{*}{ Health records $s^{\star * *}$} & yes & $78.2 \%$ & $7.6 \%$ & $14.1 \%$ & \multirow{3}{*}{0.000} \\
\hline & no & $63.2 \%$ & $14.2 \%$ & $22.6 \%$ & \\
\hline & not known & $61.6 \%$ & $11.6 \%$ & $26.7 \%$ & \\
\hline & $<1$ year & $42.0 \%$ & $21.7 \%$ & $36.3 \%$ & \\
\hline & $1-2$ years & $57.0 \%$ & $14.0 \%$ & $29.0 \%$ & \\
\hline Inflow duration ${ }^{\star * *}$ & $3-4$ years & $65.0 \%$ & $13.7 \%$ & $21.3 \%$ & 0.000 \\
\hline & 5 - 9 years & $71.5 \%$ & $8.7 \%$ & $19.8 \%$ & \\
\hline & $\geq 10$ years & $81.1 \%$ & $8.0 \%$ & $10.9 \%$ & \\
\hline
\end{tabular}




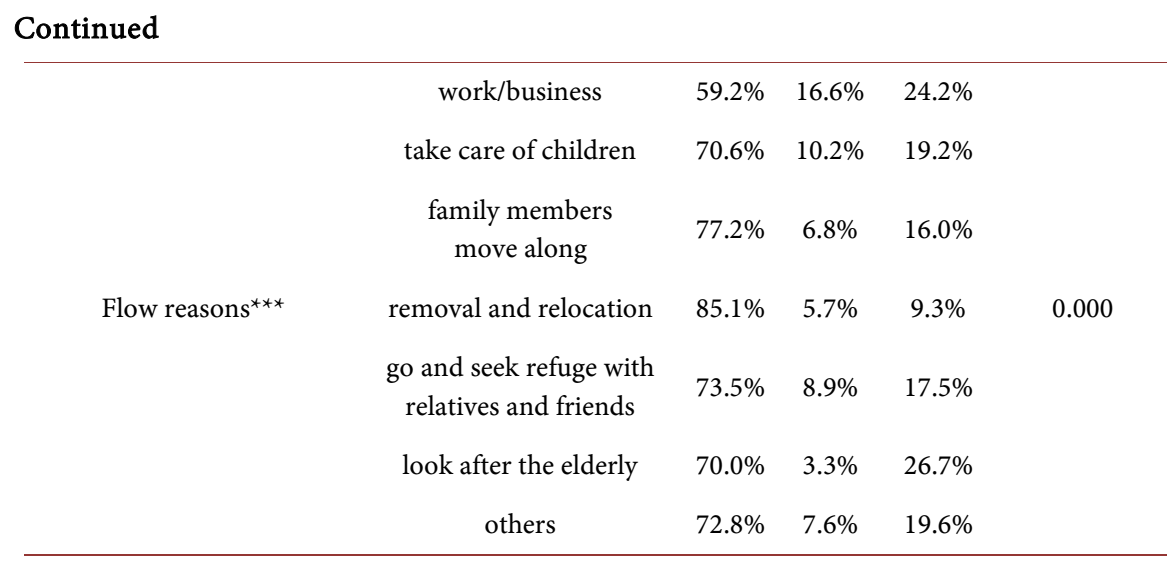

Note: ${ }^{* *} P<0.01,{ }^{*} P<0.1$.

$41.7 \%$ of the male and female, $56.5 \%$ and $43.5 \%$ of the agricultural and non-agricultural households respectively; the married elderly are the vast majority, while the unmarried elderly are only $18.7 \%$. Specifically, more than $65 \%$ of the FEP, men or women, choose to stay in the inflow area, and the proportion of the male FEP is lower than that of women by nearly 3 percentage points, which indicates that compared with the female FEP, the residing preference of male is weaker.

Moreover, $70.5 \%$ of the married FEP who choose to "Yes"- "Plan to reside in the local area for a long time ( $\geq 5$ years)", while only $65.2 \%$ of the unmarried FEP choose "Yes", which shows that the instability of marital status is not conducive to the FEP to have a strong residing preference; the willingness to stay of the FEP with agricultural household registration is nearly 10 percentage points lower than that of non-agricultural, indicating that the residing preference of the non-agricultural FEP is stronger than the non-agricultural. Finally, the FEP in China is characterized by a lower level of education. The FEP with higher education background is less than $10 \%$, while the medium and low is $93 \%$ (the elderly with low education background is $48.8 \%$ ). Besides, with the improvement of education level, the residing preference of the FEP is also increasing, which are $66.8 \%, 70.8 \%$, and $79.9 \%$ respectively, demonstrating that the education level and the residing preference of the FEP are positively correlated.

\section{Social Characteristics of the FEP in China}

The social integration of the FEP in the inflow area is the main manifestation of their social characteristics. Specifically, the residing preference of the elderly who have established health records is $15 \%$ higher than that has not been established; the residing preference of the elderly who have already purchased a house in the inflow area is much higher than the one who did not purchase; and the residing preference of the elderly who flow alone is significantly lower than that of the elderly who do not flow alone. This shows that the more the social fetters to be, the higher the elderly's willingness to reside, and the better the FEP integrate into the inflow area, the more they prefer to stay. However, it is interesting that the elderly without jobs have a higher willingness to stay than the one who have 
a job. This may be caused by the short-term employment or business pressure of livelihood, which makes the elderly not adapt to the living environment in the inflow area.

\section{Flow Characteristics of the FEP in China}

The flow characteristics are mainly manifested in the inflow duration and flow reasons of the FEP. The longer the inflow duration is, the stronger the residing preference will be. The residing preference of the FEP in less than one year of the inflow time are $42 \%$, and $81.1 \%$ are more than 10 years. Besides, the number of "Yes" (plan to stay) answer of the residing preference gradually increases with inflow duration.

The causes of the migration are the key points of the flow of the FEP in China. According to Figure 2, the subjective reasons for the flow are reflected in the two aspects of work/business and family migration or relocation, $36.1 \%$ and $25.7 \%$ of the total sample respectively, rather than the traditional reason that the flow of the elderly is to look after their children or grandchildren, which is only $12.7 \%$. And the residing preference of this traditional reason is relatively low compared with others. Even though the inter-administrative regional demolition is relatively less, there are also $5.7 \%$ of the elderly migrating to other regions due to the family removal and relocation with the accelerated process of urbanization in China, and the residing preference of the FEP on this reason is the highest. This is also in line with the high residing preference of the elderly who have purchased a house mentioned above, thus the stable living environment becomes an important indicator of the residing preference. Besides, the traditional clan concept and the different social order pattern in China for the retirement life of the elderly also brings the reasons such as going to stay with or relying on their relatives and friends, and it is far higher than the family relocation, which reaches $11.4 \%$. From the above demographic characteristics, it can be seen that the main force of the FEP in China is the young elderly. Because of the improvement of medical conditions and level, there are also $0.6 \%$ of the elderly choosing to take care of the older elderly. In addition, there are some other reasons, accounting for $7.8 \%$.

\section{Empirical Analysis of the Residing Preference of the FEP in China}

\subsection{Research Hypothesis and Research Model}

Based on the analysis of the characteristics and current situation of the floating elderly in China, we take the residing preference as the dependent variable, and take the gender, age, marital status, household registration, education level, health education, working situation, local housing purchase, endowment insurance, number of people living together, individual flow, health records, inflow duration and inflow reason as the independent variables. According to Bourdieu's "three capital" theory, the education level and health education are divided into cultural capital, the working situation, local housing purchase and the 
participation of endowment insurance are classified into economic capital, and the number of people living together, individual flow, health records, inflow duration and inflow reasons are selected as social capital. We assume that when each variable in the three types of capital is gradually added to the model for analyzing the residing preference, it will increasingly strengthen the interpretation of the influence on residing preference in the discussion. That is to say, the combination of each variable in the three types of capital can effectively help to explore the factors affecting the residing preference of the FEP in China.

We use the corresponding question-and-answer items in the questionnaire as the independent variables. As for the problem that the model cannot be solved due to too few or missing samples of individual variable categories, the corresponding data has been processed together. The detailed definition and evaluation of variables are shown in Table 2 before. In terms of Table 5, each independent variable and dependent variable are tested for significance and the details of each independent variable and dependent variable are also counted. After testing, we have found that except for the "number of people living together" is not significant, all other variables have passed the significance test. Therefore, it is excluded in the independent variables of the residing preference, and will also not be considered in the model construction. According to the division of the four major categories, a main effect model of multiple logistic regression is adopted as the model framework, and the interaction between the independent variables is not investigated temporarily. Three models are constructed with "No" (not plan to stay) in the residing preference as the reference category, and they have a progressive relationship. From model 1 to model 3, three types of capital variables are gradually added. The specific model construction is as follows:

Model 1: Socio-demographic characteristics + variables in economic capital.

Model 2: Model $1+$ variables in cultural capital.

Model 3: Model $2+$ variables in social capital.

\subsection{Empirical Analysis of Residing Preference}

\section{Model 1: Setting Explanation and Analysis}

Model 1 examines the effects and predictions of socio-demographic factors and economic capital factors on the residing preference of the FEP in the samples (see Table 6), and it has passed the model fitting test, which indicates that this model has the statistical significance. The results of "likelihood ratio test" show that the two variables of "gender" and "household registration" in socio-demographic characteristics have not passed the significance test, while all variables in economic capital have passed the test. If these two variables are not added, the "goodness of fit" of the entire model is far lower than that of the added one. Therefore, in order to improve the overall explanatory power of Model 1, the two variables are finally selected to be added. However, the Pearson Chi-Square significance value of the goodness of fit in the whole model is only 
Table 6. Multiple logistic regression results of the residing preference of the FEP in Model 1 .

\begin{tabular}{|c|c|c|c|}
\hline \multirow{2}{*}{ Variable } & \multicolumn{2}{|c|}{ Model 1} & \multirow{2}{*}{ Likelihood Ratio Test } \\
\hline & Yes & I Don't Know & \\
\hline \multicolumn{4}{|c|}{ Socio-demographic Characteristics } \\
\hline Male & 0.881 & 0.898 & Gender (not significant) \\
\hline Age: 60 - 63 & $1.309^{* *}$ & $0.790^{*}$ & \multirow{2}{*}{$\operatorname{Age}^{* * *}$} \\
\hline Age: $64-67$ & 1.070 & 0.891 & \\
\hline Married & $0.793^{\star}$ & 0.943 & Marital status* \\
\hline Agricultural & 0.950 & 1.016 & Household registration (not significant) \\
\hline \multicolumn{4}{|c|}{ Economic Capital } \\
\hline Employed & $0.578^{\star * *}$ & $0.762^{* *}$ & Working situation ${ }^{\star * *}$ \\
\hline Purchased & $6.170^{* * *}$ & $1.516^{* * *}$ & Local housing purchase $e^{\star * *}$ \\
\hline Participated & 0.851 & 0.350 & \multirow{2}{*}{ Endowment insurance ${ }^{*}$} \\
\hline Not Participated & 0.847 & 0.376 & \\
\hline \multicolumn{4}{|c|}{ Model Fitting Information: $3525.372^{\star * *}$} \\
\hline Pseudo $R^{2}: 0.577$ & \multicolumn{3}{|c|}{ Goodness of fit: 0.214} \\
\hline & Samples: & 7; Note: ${ }^{\star * \star} P<0$. & ${ }^{\star *} P<0.05,{ }^{\star} P<0.1$ \\
\hline
\end{tabular}

0.214 , so Model 1 is obviously not enough for the interpretation of residing preference, which also provides modeling significance for the later model. In addition, the model has the highest accuracy in predicting the choice tendency of "Yes" (plan to stay), reaching $99.9 \%$, while the prediction of other residing choices is very low. The overall prediction accuracy of the model is $69.5 \%$. In general, the explanatory ability of Model 1 to the whole is insufficient.

According to the regression results, "age", "gender", "working situation" and "local housing purchase" have a significant impact on the answer "I Don't Know" of residing preference of the FEP, while the effects of "age", "gender", "marital status", "household registration" on the answer "Yes" (plan to stay) of residing preference are less significant. The probability of "Yes" (plan to stay) answer of the floating elderly who have already purchased a house is 6.17 times that of not buying, and they are more inclined to stay for a long time. Besides, with the increase of age, the older elderly's willingness to stay will decrease. This is in sharp contrast to the previous trend that the age can affect the flow of the elderly. The possibility of "Yes" (plan to stay) answer of the floating elderly with agricultural household registration is only 0.881 times that of non-agricultural, and the non-agricultural floating elderly are more likely to be long-term residents. "Endowment insurance" and "household registration" have no significant influence on the "I Don't Know" and "Yes" (plan to stay) answers of the residing preference of the FEP.

\section{Model 2: Setting Explanation and Analysis}


On the basis of Model 1, two variables of "education level" and "health education" in cultural capital are gradually added. At the same time, the two variables, "gender" and "household registration", in Model 1 that do not pass the likelihood ratio test are removed in Model 2. Compared with Model 1, Model 2 improves the goodness of fit and pseudo $\mathrm{R}^{2}$ value as a whole (see Table 7 ). The fitting information of Model 2 is still good, but the variable of education level has not passed the test, and the significance of the same dependent variable is not high between each small item. In addition, Model 2 is the same as model 1 in predicting the choice tendency of "Yes" (plan to stay), and the prediction of other residing preference choices is still very low. The overall prediction accuracy of Model 2 is $69.7 \%$, which is 0.2 percentage points higher than the Model 1 . In a word, the overall explanatory power of Model 2 still needs to be improved, which lays the foundation for the setting of Model 3.

Compared with Model 1, each small item of the two variables in the socio-demographic characteristics and economic capital does not change too much in Model 2, demonstrating that the adding of cultural capital variables has little effect on the residing preference in these two variables, and Model 2 is relatively stable. Specifically, the FEP who once received the health education have stronger residing preference; and the education level has little influence on the residing preference, which is quite different for many studies mentioned before. That is

Table 7. Multiple logistic regression results of the residing preference of the FEP in Model 2.

\begin{tabular}{|c|c|c|c|}
\hline \multirow{2}{*}{ Variable } & \multicolumn{2}{|c|}{ Model 2} & \multirow{2}{*}{ Likelihood Ratio Test } \\
\hline & Yes & I Don't Know & \\
\hline \multicolumn{4}{|c|}{ Socio-demographic Characteristics } \\
\hline Age: $60-63$ & $1.305^{\star *}$ & $0.782^{*}$ & \multirow[b]{2}{*}{$\operatorname{Age}^{* * *}$} \\
\hline Age: $64-67$ & 1.066 & 0.886 & \\
\hline Married & $0.814^{*}$ & 0.966 & Marital status* \\
\hline \multicolumn{4}{|c|}{ Economic Capital } \\
\hline Employed & $0.549^{\star}$ & $0.742^{\star *}$ & Working situation ${ }^{* *}$ \\
\hline Purchased & $6.124^{* * *}$ & $1.504^{* * *}$ & Local housing purchase ${ }^{\star * \star}$ \\
\hline Participated & 1.097 & 0.350 & \multirow{2}{*}{ Endowment insurance ${ }^{\star}$} \\
\hline Not Participated & 1.114 & 0.376 & \\
\hline \multicolumn{4}{|c|}{ Cultural Capital } \\
\hline Received & 1.407 & 1.173 & Health education ${ }^{\star * *}$ \\
\hline Low & 0.928 & 0.977 & \multirow{2}{*}{$\begin{array}{l}\text { Education level } \\
\text { (not significant) }\end{array}$} \\
\hline Medium & 0.946 & 0.962 & \\
\hline \multicolumn{4}{|c|}{ Model Fitting Information: $3537.908^{\star * *}$} \\
\hline Pseudo $\mathrm{R}^{2}: 0.578$ & \multicolumn{3}{|c|}{ Goodness of fit: 0.609} \\
\hline & 4907; Not & $0.01, * * P<0.05$ & 0.1 \\
\hline
\end{tabular}


to say, for the FEP, it is not the higher the educational level is, the stronger the residing preference will be now. Besides, the adding of cultural capital has improved the goodness of fit by 0.395 , which indicates that cultural capital has a great influence on the residing preference of the FEP, but the education level in cultural capital fails to pass the significant test, implying that health education, in fact, has a very high impact on the residing preference.

\section{Model 3: Setting Explanation and Analysis}

As the "education level" variable fails to pass the significance test in Model 2, it is excluded in Model 3, and the social capital variables are then added based on Model 2. It has been found that the "inflow reason" is not significant in Model 3. After excluding it, the goodness of fit and pseudo $\mathrm{R}^{2}$ are 0.91 and 0.615 respectively. In order to further improve the goodness of fit and pseudo $\mathrm{R}^{2}$ value to make Model 3 the best, the excluded socio-demographic characteristics and the excluded "education level" variables in Model 2 are gradually added. When the two independent variables "endowment insurance" and "education level" are not added, the goodness of fit is increased from the original 0.952 to 0.987 . Besides, since the "endowment insurance" and "education level" don't pass the significance test, in order to optimize the model, we choose to give up these two variables and only add "gender" and "household registration" as the socio-demographic characteristic variables in Model 3. In the end, the goodness of fit and pseudo $\mathrm{R}^{2}$ reach 0.987 and 0.616 respectively (see Table 8); in addition, the overall prediction effect of Model 3 is also greatly improved, so it reaches the optimal results (see Table 9).

In Model 3, each variable in social capital added has passed the significance test, and the pseudo $\mathrm{R}^{2}$ is $3.9 \%$ higher than that in Model 2 for the explanatory power. Each newly added variable is significant, indicating that the social capital factors have the most significant influence on the residing preference of the FEP. Compared with Model 1 and Model 2, cultural and economic capital factors have not changed too much in Model 3. Furthermore, in social capital factors, the residing preference of the elderly who migrate alone is 0.448 times higher than that of the elderly who move along with others, which indicates that the residing preference of the "individual flow" elderly is actually lower; while the residing preference of the elderly who have established the health records is much higher than those who have not, and the "Yes" (plan to stay) is 1.494 times than the "I Don't Know", which suggests that the social care and social integration in the inflow area play an important role in improving the residing preference of the elderly who have not planned to stay. Moreover, as the flow time continues to increase, the residing preference becomes stronger and stronger. This is similar to the psychological sense of belonging. Finally, the adding of social capital variables in Model 3 contributes 0.378 to the goodness of fit, demonstrating that social capital has a greater strength in interpreting the residing preference of the FEP.

From Model 1 to Model 3, it shows that after continuously adding various capital variables, it is more reasonable and perfect to interpret the residing 
Table 8. Multiple logistic regression results of the residing preference of the FEP in model 3 .

\begin{tabular}{|c|c|c|c|}
\hline \multirow{2}{*}{ Variable } & \multicolumn{2}{|c|}{ Model 3} & \multirow{2}{*}{ Likelihood Ratio Test } \\
\hline & Yes & I Don't Know & \\
\hline \multicolumn{4}{|c|}{ Socio-demographic Characteristics } \\
\hline Male & 0.909 & 0.913 & Gender (not significant) \\
\hline Age: 60 - 63 & 1.119 & $0.775^{* *}$ & \multirow{2}{*}{$\operatorname{Age}^{* * *}$} \\
\hline Age: $64-67$ & 0.999 & 0.875 & \\
\hline Married & 1.236 & 1.125 & Marital status (not significant) \\
\hline Agricultural & 0.844 & 1.016 & Household registration ${ }^{*}$ \\
\hline \multicolumn{4}{|c|}{ Economic Capital } \\
\hline Employed & $0.557^{* * *}$ & 0.822 & Working situation ${ }^{\star * *}$ \\
\hline Purchased & $5.207^{* * *}$ & $1.519^{* * *}$ & Local housing purchase ${ }^{\star * *}$ \\
\hline \multicolumn{4}{|c|}{ Cultural Capital } \\
\hline Participated & 1.049 & 1.155 & Health education (not significant) \\
\hline \multicolumn{4}{|c|}{ Social Capital } \\
\hline Yes & $0.448^{\star * *}$ & $0.704^{* * *}$ & Individual flow ${ }^{* * *}$ \\
\hline Established & $1.494^{\star *}$ & 0.763 & \multirow[b]{2}{*}{ Health records ${ }^{* * *}$} \\
\hline Not Established & 0.816 & $0.694^{* *}$ & \\
\hline$<1$ year & $0.196^{* * *}$ & 1.178 & \multirow{4}{*}{ Inflow duration ${ }^{* * *}$} \\
\hline $1-2$ years & $0.396^{* * *}$ & $1.433^{* *}$ & \\
\hline $3-4$ years & $0.374^{* * *}$ & 1.041 & \\
\hline 5 - 9 years & $0.645^{* * *}$ & $1.519^{* * *}$ & \\
\hline \multicolumn{4}{|c|}{ Model Fitting Information: $3889.460^{\star * *}$} \\
\hline Pseudo $R^{2}: 0.616$ & \multicolumn{3}{|c|}{ Goodness of fit: 0.987} \\
\hline & Samples: 490 & Jote: ${ }^{* * *} P<0.01$, & $<0.05,{ }^{\star} P<0.1$ \\
\hline
\end{tabular}

Table 9. Prediction of the residing preference of the FEP in Model 3.

\begin{tabular}{ccccc}
\hline \multirow{2}{*}{ Test Results } & \multicolumn{3}{c}{ Prediction } \\
\cline { 2 - 5 } & Yes & No & I Don't Know & Correct Pct. (\%) \\
\hline Yes & 3275 & 10 & 125 & $96.0 \%$ \\
No & 407 & 13 & 120 & $2.4 \%$ \\
I Don't Know & 752 & 13 & 192 & $20.1 \%$ \\
Correct Pct. (\%) & $90.4 \%$ & $0.7 \%$ & $8.9 \%$ & $70.9 \%$ \\
\hline
\end{tabular}

preference of the FEP. This can lay an empirical foundation for the targeted public policy suggestions based on the issues found in the model. In terms of the parameter estimates, the final model 3 is as follows:

$\mathrm{G} 1=\mathrm{LOG}[\mathrm{P}(\mathrm{Yes}) / \mathrm{P}(\mathrm{No})]=2.233-0.09$ gender $1+0.112$ age $1-0.001$ age $2+0.212$ marital status $1-0.17$ household registration $1-0.585$ working 
situation $1+1.65$ local housing purchase $1-0.174$ health education $0+0.048$ health education $1-0.803$ individual flow $1+0.401$ health records $1-0.203$ health records 2 - 1.631 inflow duration 1 - 0.926 inflow duration $2-0.983$ inflow duration 3 - 0.439 inflow duration 4 .

G2 $=$ LOG $[\mathrm{P}(\mathrm{I}$ don't know)/P $(\mathrm{No})]=0.779-0.091$ gender $1-0.255$ age 1 -0.134 age $2+0.118$ marital status $1+0.016$ household registration $1-0.197$ working situation $1+0.418$ local housing purchase $1+0.035$ health education 0 +0.144 health education $1-0.35$ individual flow $1-0.271$ health records 1-0.365 health records $2+0.164$ inflow duration $1+0.36$ inflow duration $2+$ 0.04 inflow duration $3+0.418$ inflow duration 4 .

G3 $=0$ (control group)

\section{Major Findings and Public Policy Suggestions}

\subsection{Major Findings}

From the above model setting and discussion, it can be found that the residing preference of the FEP in China is relatively strong now. According to the 4907 effective samples, $69.5 \%$ of the FEP plan to stay in the inflow area regardless of the reasons. The floating elderly make residence decisions in terms of their own migration conditions, backgrounds and the public services in the inflow areas, such as community health education, health status registration, health check-up, etc., which, as a matter of fact, is rational, not simply for the pursuit of high quality of life or good living environment.

Besides, there are many factors affecting the residing preference of the FEP. On the basis of multiple logistic regression model, the proportion of the dependent variables in the model is significantly increased after adding the social capital variables through the stepwise regression method, which shows that the variables in the social capital have a more significant impact on the residing preference of the FEP. Although factors such as "age" and "marital status" in the socio-demographic characteristics have an effect on the residing preference, the results are not ideal and satisfactory in the significance test.

In economic capital, the three variables in economic capital, "working situation", "local housing purchase" and "endowment insurance", have passed the significance test, and the "working situation" and "local housing purchase" exert the most influence on the residing preference of the FEP, so the economic conditions also become the influencing factors of the residing preference; among the cultural capital factors, the "education level" is not an important factor to restrict the residing preference, instead, the "health education" is the significant factor; while in social capital, all variables have passed the significance test, and the model explanatory power has been greatly improved. The longer the flow duration, the companion flow and the establishment of health records are, the stronger the residing preference of the FEP will be. In view of the above findings, we then attempt to propose some public policy suggestion to enhance the residing preference of the FEP. 


\subsection{Public Policy Suggestions}

In the social aspect, the government needs to consummate the related policy, and to guide the community to perfect the old-age system. At present, China's public service system is based on the household registration. In order to improve the efficiency of public service, China must respond to the problem of floating population, especially the FEP, whose demands for the public services are particularly prominent. Their comments of the public service can directly affect their residing preference to stay in the inflow place. As the core factor of residing preference, social capital can maximize it by constructing the service. The first is to carry out some positive policies to encourage the elderly to move in groups and take care of them so as to reduce their psychological loneliness and the pressure of self-care in life. The second is to enhance the community services for the floating elderly, meeting the needs of the elderly in material assistance, life care, spiritual comfort and health care to strengthen the trust and reliance of the local community. The third is to timely check and register the long-term living floating elderly and improve the off-site settlement measures for public services such as medical insurance in order to encourage them to settle down.

In the economic aspect, it is suggested to improve the residence intention of the floating elderly population from the aspects of employment, insurance and medical security. The above empirical study shows that economic capital is an important factor affecting the residing preference of the FEP. The FEP in China now are mainly the low-age elderly. With the improvement of medical conditions, the physical condition of the young elderly is better than before. According to the data, less than $30 \%$ of the floating elderly are employed, but more than $50 \%$ of them are willing to stay in the local area. Therefore, the government should support and help the young elderly to re-employ or re-enterprise, so that they can also become a part of creating social wealth and social value. In addition, the empirical study also finds that the purchase of endowment insurance, the registration of health records and whether to receive the health education have some influence on the residing preference of the FEP. In order to further improve the residing preference and reduce the burden of public service brought by the rapid flow of the elderly, the government should continue to make efforts on propaganda of endowment insurance purchasing, and actively promote the establishment of health records, especially for the floating elderly with a history of major diseases. The worldwide 2019-nCoV is a typical example since the majority of the dead are the elderly. Moreover, the government can also strengthen the assistance for the elderly with financial difficulties, ensuring that they can afford to see a doctor and do some self-care; at the same time, give some preferential policies in the housing purchase, medical services and so on to alleviate their economic worries about the re-consumption in the inflow area.

In terms of culture, a variety of activities aimed at the elderly mobile population should be organized to provide a high level of health services. Although cultural capital is found to be a soft factor in the empirical analysis, it is of great 
significance to improve the psychological health of the floating elderly. Therefore, the government and the community can, on the one hand, regularly introduce the health knowledge to the elderly through the community service to make them have a high level of awareness on the relevant health knowledge and their own health care; on the other hand, strengthen the participation of the community activities among the floating elderly to deepen the sense of belonging to the inflow area, which, in fact, can play a considerable role in promoting their residing preference with the increase of their inflow time.

\section{Conclusion}

By applying Pierre Bourdieu's cultural capital, economic capital and social capital into the analysis of the residing preference in China's floating elderly population (FEP), this study has not only conducted various regression modeling analysis, but also put forward some public policy suggestions on enhancing the residing preference of the FEP. It is not difficult to see that there are many factors affecting the residing preference, which exist both in the various individual and social characteristics and in the interaction and influence among cultural, economic and social capital. The Model 1, 2, 3 have a good number of indicators, significantly reflecting the influence of the variables of different capitals on the residing preference. Among them, the social capital exerts the most remarkable influence. Besides, the residing preference of the FEP in China is relatively strong now. Therefore, it is of positive significance to provide public resources and facilities for the FEP, and at the same time to improve their residing preference for reducing the burden of public management and public health. With the continuous development of China's aging population and the improvement of modern transportation, the researches on the FEP, a specific group of the elderly in China, may continue to expand, and the regional research on the FEP tends to become a hot topic in the future, especially in the context of regional and economic integration.

\section{Conflicts of Interest}

The authors declare no conflicts of interest regarding the publication of this paper.

\section{References}

Bourdieu, P. (1986). The Forms of Capital. In J. G. Richardson (Ed.), Handbook of Theory and Research for the Sociology of Education (pp. 241-258). New York: Greenwood.

Chen, S., \& Wu, H. (2016). Settlement Intention and Influence Factors of the Elderly Migrants in Cities: Based on Sampling Survey in Fujian Province. Academic Journal of Jinyang, 2, 97-104.

Chen, Y. (2015). The Old Age in Population Mobility-Factors Influencing the Flow of Elderly Population in Current China. Scientific Research on Aging, 3, 49-56.

Coleman, J. S. (1998). Social Capital in the Creation of Human Capital. American Journal 
of Sociology, 94, S95-S120. https://doi.org/10.1086/228943

Duan, C., Lv, L. et al. (2013). Major Challenges for China's Floating Population and Policy Suggestions: An Analysis of the 2010 Population Census Data. Population Research, 37, 17-24.

He, D., \& Liu, H. (2019). Population Aging Trend, Impact and Coping Strategies in China. Journal of the Party School of the Central Committee of the CPC (Chinese Academy of Governance), 23, 84-90.

Hou, J., \& Li, X. (2017). The Analysis of the Status of China's Floating Elderly Population and It's Influencing Factors. Population Journal, 39, 62-70.

Jiang, X., Hou, J. et al. (2004). Migration of the Elderly in China and Aging Population in Urban and Rural Areas. In China's Census Office of State Council, Population and Social Science and Technology Statistics Department of National Bureau of Statistics (Eds.), Proceedings of the Fifth National Census Scientific Symposium (pp. 916-928). Beijing: China Statistics Press.

Jing, X. (2019). Elderly Migrants in China: Spatial Distribution and Residence Willingness in Destination-Based on the Dynamic Monitoring Data of Floating Population in 2015. Population and Development, 25, 34-43.

Jing, X., \& Zhu, J. (2015). Study on the Elderly Migrants' Desire of Settling in the City. Journal of Sichuan Agricultural University, 33, 113-118.

Li, F., Gong, W. et al. (2016). On the Residential Intention of Elderly Migrants in the Perspective of Theory of Bourdieu. Population and Society, 32, 3-12.

Li, S. (2011). Residential Consciousness of Chinese Migrant Elderly. Northwest Population Journal, 32, 69-72.

Li, Y. (2007). Social Capital, Social Exclusion and Wellbeing. In A. Scriven, \& S. Garman (Eds.), Public Health: Social Context and Action (pp. 60-75). London: Sage Publications Ltd.

Lv, L., Yang, G. et al. (2019). Elderly Migration in China: Definition, Classification and Trend-Analysis from China's 2015 One-Percent National Population Sample Survey. Human Resources Development of China, 36, 81-92.

Ma, A., \& Chow, W. S. (2006). Economic Impact of Elderly Amenity Mobility in Southern China. Journal of Applied Gerontology, 25, 275-290. https://doi.org/10.1177/0733464806289401

Meng, X. (2009). Adaptability of the Floating Elderly Population in Beijing. China Urban Studies, 172-179.

Qi, M. (2004). Theoretical and Empirical Analysis on Elderly Migration (pp. 47-48). Beijing: China Population Press.

Shen, Q. (2012). Factors Influencing the Floating Population's Residence Intention-Based on the Survey of Six Cities in China. Economic Research Guide, 148, 92-95. 